\title{
Síndrome de Sjögren asociado a alteraciones hepáticas: a propósito de dos casos en Atención Primaria
}

\author{
J. A. Mengual Pavía, J. A. Oltra Masanet ${ }^{1}$ \\ Médico Residente de 3o año de Medicina Familiar y Comunitaria. \\ 'Médico de Familia. Tutor Docente. Centro de Salud de PEGO. Alicante.
}

\section{RESUMEN}

El síndrome de Sjögren (SS) es una enfermedad autoinmune de afectación multiorgánica, caracte rizada por la sequedad de mucosas en general y por afectaciones extraglandulares como artritis, fenómeno de Raynaud y afectación hepática entre otras.

Presentamos dos casos de SS en los que la afectación hepática con aumento de transaminasas fue clave para el diagnóstico de la enfermedad.

El médico de familia se halla en una situación privilegiada en la detección de enfermedades mul tiorgánicas como el SS, ya que la visión en conjun to del paciente así como su seguimiento son más habituales, cosa más difícil en otras especialida des.

Palabras clave: Síndrome de Sjögren. Hígado. Atención Primaria.
Sjögren syndrome associated to hepatic altera tions: two cases in Primary Health Care

\begin{abstract}
The Sjögren syndrome (SS) is a self-inmune ill ness of multiorganic affectation, distinguished by the dryness of general mucous membranes and extraglandular affectations such as arthritis, Ray naud phenomenon and hepatic affectation in addi tion to others.

We display two cases of SS where the hepatic af fectation with the increase of transaminases was the key for the diagnosis of the illness.

The family doctor finds himself in a privileged situation in the detection of multiorganic illnesses such as SS, since the overall view of the patient as well as his continuation are more usual, something more difficult in other fields.
\end{abstract}

Key words: Sjögren syndrome. Liver. Primary Health Care.

\section{INTRODUCCIÓN}

El síndrome de Sjögren (SS) es una enfermedad crónica autoinmune de etiología desconocida, caracterizada por una infiltración linfoide principalmente en glándulas salivares y lacrimales. Se presenta de forma aislada (SS primario) o asociado a otras enfermedades autoinmunes (SS secundario) ${ }^{1}$, tales como la artritis reumatoide, esclerodermia, lupus eritematoso sistémico, dermatomiositis o enfermedad mixta del tejido conectivo ${ }^{2}$. En las formas secundarias, la artritis reumatoide es la entidad asociada con mayor frecuencia en más del $30 \%$ de las ocasiones. Su prevalencia es de un $0,44 \%$ sobre

Recepción: 27-05-02 Aceptación: 04-11-02 
la población general, siendo de 9 a 10 veces más frecuente en mujeres que en hombres. El pico de edad se encuentra en los 50 años.

La clínica se caracteriza por la sequedad de las mucosas que aparece cuando se ha perdido al menos la mitad de las glándulas secretoras. Se manifiesta con un ojo seco, doloroso y enrojecido, y en el caso de la mucosa oral, con una sequedad bucal que hace necesaria la ingesta de abundantes líquidos y tumefacción de las glándulas salivares mayores de manera permanente o transitoria. Todos estos síntomas estarán presentes al menos durante tres meses. Otras glándulas exocrinas pueden verse afectadas también, como los genitales femeninos en donde provoca sequedad vaginal, dispareunia o prurito $^{3}$.

Las manifestaciones extraglandulares más frecuentes son las artralgias o artritis (65\%), el fenómeno de Raynaud (40\%), las linfadenopatías $(20 \%)$ y las alteraciones pleuropulmonares, renales o hepáticas con alrededor de un $10 \%$ cada una de ellas. Hay manifestaciones menos frecuentes como vasculitis, neuropatías periféricas, linfomas, esplenomegalia o miositis. Con respecto a las manifestaciones gastrointestinales, que son las que relacionan a nuestras pacientes, están descritas alteraciones a nivel hepático, ya sea a nivel de pruebas hepáticas, hepatitis autoinmune, cirrosis biliar primaria (CBP) o fibrosis portal. En un 25$30 \%$ de pacientes con SS primaria existe una leve hepatomegalia, con o sin elevación de enzimas obstructivas o autoanticuerpos antimitocondriales.

En cuanto a los datos de laboratorio, se aprecia una elevación de la velocidad de sedimentación globular (VSG) en un 60-90\% de casos y de la proteína $\mathrm{C}$ reactiva (PCR) $(5 \%)$, leucopenia, plaquetopenia, anemia, aumento de transaminasas y gamma-GT (GGT) o fosfatasa alacalina (FA). También aparecen datos más específicos como anticuerpos antinucleares (ANA) en un $90 \%$ de los casos, Anti Ro $(55 \%)$ o Anti La (40\%) y Factor Reumatoide (FR) (60-90\%).

Para el diagnóstico se han utilizado los criterios europeos para la clasificación del SS de 1934, aunque en la actualidad en Estados Unidos se utilicen los de Fox (Tabla I).

\section{CASOS CLÍNICOS}

\section{Caso 1}

Mujer de 75 años de edad con el único antecedente de colecistectomía en 1992.

En septiembre de 1998 presenta cuadro de astenia y anorexia con exploración física anodina, por lo que se le realiza analítica y se detecta GGT 654,
Tabla I

CRITERIOS EUROPEOS PARA LA CLASIFICACIÓN DEL SS

Síntomas oculares de sequedad

Es positivo con una respuesta afirmativa a una de las tres preguntas siguientes: a) ¿ha tenido usted la sensación de tener sus ojos secos cada día, los últimos tres meses?; b) ¿tiene usted sensación de tener arenilla 0 tierra en sus ojos?; y c) ¿precisa ponerse cada día tres o más veces lágrimas artificiales?

\section{Síntomas de sequedad oral}

Respuesta afirmativa a una de las tres preguntas siguientes: a) ¿Tiene usted sensación a diario de boca seca los últimos tres meses?; b) ¿Recuerda usted que se le hayan hinchado sus parótidas ya adulto?; y c) ¿Tiene usted que beber líquidos para deglutir alimentos secos?

\section{Signos oculares}

Se confirma con una de las dos siguientes pruebas: un test de Schrimer de cinco o menos milímetros en cinco minutos o una puntuación de cuatro o más en el Rosa de Bengala en la escala de Bijsterveld.

Alteración objetiva de las glándulas salivales

Objetivación de la sequedad oral por medio de una de las tres pruebas siguientes: a) gammagrafía de las glándulas salivares con déficit difuso de captación; b) sialografía con alteraciones difusas acinares y ductales; y c) flujo salivar sin estimular de 1,5 $\mathrm{ml} 0$ menos en 15 minutos.

\section{Datos histopatológicos}

Es positivo ante la presencia de uno o más focos de 50 células mononucleadas / $4 \mathrm{ml}$ (cada foco corresponde al infiltrado existente en esos $4 \mathrm{ml}$ ).

Presencia de autoanticuerpos

Este criterio requiere al menos la presencia de uno de los siguientes autoanticuerpos: anticuerpos anti -Ro, anticuerpos anti -La, anticuerpos antinucleares y factor reumatoide.

Un paciente tiene SS primario si reúne cuatro de los seis criterios. Si a éstos se suman los de otra enfermedad autoinmune sistémica (lupus, artritis reumatoide, esclerodermia, dermatomiositis o enfermedad mixta), el paciente padece SS secundario.

FA 348, transaminasa glutamicooxalacética (GOT) y transaminasa glutamicopirúvica (GPT) normales. En el hemograma se apreciaba una trombopenia de 105.000 plaquetas. Revisada la historia clínica aparece una analítica en 1987 con una mínima alteración enzimática y un aumento leve de GGT y FA.

La paciente ante esta alteración fue remitida a consulta de Digestivo pero prefirió acudir a un digestólogo privado donde se le realizó una ecografía abdominal con resultado de hígado y vía biliar nor- 
mal y ausencia de vesícula biliar. Se llegó al diagnóstico de dispepsia postcolecistectomía y recibió tratamiento con ácido ursodesoxocólico.

En marzo de 1999, la paciente nos consultó por cuadro de sequedad ocular y se le recetaron lágrimas artificiales siguiendo desde entonces este tratamiento de forma ininterrumpida.

Un año más tarde (marzo de 2000) nos consultó de nuevo por presentar xerostomía y se objetivó sequedad de la mucosa oral con lengua geográfica. Ante la sospecha de SS se pidió analítica dirigida con el resultado de ANA positivo, anti-Ro positivo, anti-La positivo y GGT y FA con cifras similares a las obtenidas dos años atrás. En el hemograma persistía una trombopenia moderada de 133.000 plaquetas.

Con estos resultados, se remitió a consulta de medicina interna para confirmar la sospecha de SS.

Posteriormente, como la paciente no cumplía cuatro de los seis criterios europeos para el diagnóstico, realizamos en nuestra consulta el test de Schrimer que resultó patológico $(0 \mathrm{~mm}$ en $5 \mathrm{mi}$ nutos).

\section{Caso 2}

Mujer de 70 años vista en nuestra consulta desde el año 1987. Previamente fue estudiada por el Servicio de Reumatología del Hospital de Alicante y se diagnosticó como poliartritis no filiada que años después se etiquetó como artritis reumatoide seronegativa.

En 1987 consultó por un episodio de tumefacción parotídea que se diagnosticó como litiasis de la glándula parótida. Se resolvió de forma espontánea pero quedó con una clínica residual de xerostomía, hiposialia y disgeusia. Durante estos años ha sufrido algún episodio de Muguet que se ha solucionado con tratamiento antifúngico.

Desde entonces, la paciente ha seguido un largo peregrinar por multitud de especialistas, entre ellos el reumatólogo y el rehabilitador por presentar brotes repetidos de poliartralgias y raquialgias, el oftalmólogo por sequedad ocular, glaucoma simple y diplopia estrábica, el ginecólogo por prurito y sequedad vaginal, y el digestólogo por dispepsia y sintomatología de reflujo gastroesofágico.

En 1998 en una analítica de control reumatológico, apareció una alteración de la bioquímica hepática (GOT 46, GPT 42, GGT 84, ferritina 230 y VSG de 34) con serología para virus negativa. Se remitió para estudio al Servicio de Digestivo. Las analíticas se mantuvieron con cifras similares de colestasis y desapareció la citolisis (GGT 78, FA 329 , GOT y GPT normales). Los ANA fueron negativos y los anti DNA positivos, con serología para virus negativa.
En 1999 se realizó a la paciente ecografía abdominal, tomografía axial computerizada (TAC) y gastroscopia con resultados de colesterolosis con hepatomegalia y gastritis crónica.

Pese a no guardar relación al caso que nos ocupa, en el año 1999 presentó clínica de cardiopatía isquémica tipo angor de esfuerzo, recibió tratamiento y se remitió a Cardiología. Más tarde, en mayo de 2000, sufrió un infarto agudo de miocardio (IAM) con enfermedad de un vaso.

En enero de 2001, a raíz del CASO 1 con el que guardaba ciertas semejanzas como son la alteración de la bioquímica hepática con colestasis y la sequedad de mucosas, pedimos analítica dirigida al diagnóstico de SS. Obtuvimos resultados positivos para anti-Ro, anti-La, anti DNA y ANA. Entonces le realizamos el test de Schrimer cuyo resultado fue patológico ( $0 \mathrm{~mm}$ en 5 minutos) con lo que se confirmó el diagnóstico de SS.

\section{DISCUSIÓN}

Con frecuencia se asocia el SS a la sequedad de mucosas ocular, orofaríngea y vaginal con poliartralgias como afectación extraglandular principal ${ }^{1,5}$. Sin embargo, esta enfermedad puede afectar prácticamente a cualquier órgano con manifestaciones clínicas y analíticas muy variopintas (Tablas II y III).

\begin{tabular}{|lc|}
\multicolumn{2}{c|}{ Tabla II } \\
\multicolumn{2}{c|}{ MANIFESTACIONES EXTRAGLANDULARES } \\
MÁS FRECUENTES EN EL SS
\end{tabular}

No es fácil llegar al diagnóstico de certeza del SS ya que deben cumplirse unos criterios más o menos estrictos que en algunos casos no están disponibles, no ya en Atención Primaria (AP) si no tampoco en ciertos hospitales de segundo o tercer nivel. 
Tabla III

\section{POSIBLES MANIFESTACIONES CLÍNICAS DEL SS}

Sequedad de ojos (queratoconjuntivitis seca), boca (xerostomía) o vagina (dispareunia).

Aumento del tamaño de las glándulas parotídeas 0 submaxilares en edad adulta.

Reumatismos: fibromialgia, artrosis erosivas y en las formas de SS secundario la presencia de conectivitis como la artritis reumatoide, lupus eritematoso sistémico, y otras.

Clínica dérmica: prurito, úlceras, púrpura, urticaria fenómeno de Raynaud, eritema anular, fotosensibilidad en escote sin localización malar o piel seca.

Digestivas: gastritis crónica, pancreatitis, malabsorción, hepatitis autoinmune.

Respiratorias: tos seca, hiperreactividad bronquial, obstrucción al flujo aéreo y neumonitis intersticiales.

Renales: acidosis tubular, nefritis intersticiales y rara vez glomerulonefritis.

Neurológicas: síndrome del túnel carpiano, mononeuritis múltiple, neuropatías sensoriales, neuropatía sensitiva del $\mathrm{V}$ par, mielopatías y demencias 0 alteraciones focales centrales.

Hemopatías: leucopenias, plaquetopenias, linfomas no Hodgkin y adenopatías.

Enfermedades autoinmunes organoespecíficas como la enfermedad de Hashimoto.

Se han definido diversos criterios para el diagnóstico de esta enfermedad. En nuestro caso hemos optado por utilizar los criterios europeos para la clasificación de SS, que a su vez es la que más aparece en las referencias bibliográficas (Tabla I).

La dificultad estriba, como ya indicábamos antes, en que de estos seis criterios dos son de difícil disposición en AP como la histopatología de las glándulas salivales o la gammagrafía salival, y que la sialografía o el flujo salivar no estimulado además de tener un acceso muy restringido, son incómodas y/o demasiado cruentas.

Por tanto, para la consecución del diagnóstico de certeza nos hemos tenido que centrar en los síntomas oculares y bucales, en la presencia de los anticuerpos anti-Ro, anti-La, ANA o FR en suero y como último criterio, en los signos oculares objetivados con el test de Schrimer o Rosa de Bengala. En nuestro caso hemos utilizado el test de Schrimer por ser más fácil y sencillo, pese a tener una especificidad de sólo un $72 \%$.

Estas limitaciones hubieran podido ser suficientes para no llegar al diagnóstico de SS, pero una vez confirmado, pensamos que el interés de estos dos casos radica en el nexo de unión relativamente inusual, a priori (según algunos compendios de Reu- matología de alrededor de un 10\%), entre el SS y la afectación hepática, que en ambos es de colestasis.

En las dos pacientes, la colestasis para su correcta filiación hubiera precisado de biopsia hepática ${ }^{6}$ para poder obtener así un diagnóstico definido ya fuera de hepatitis autoinmune, de CBP, de fibrosis portal o una mera alteración de las pruebas hepáticas con colestasis sin alteración histológica del hígado.

En la literatura revisada, hemos hallado referencias bibliográficas tanto al buscar "Afecta ción hepática autoinmune en pacientes con SS" como "Prevalencia de SS en pacientes afectos de hepatopatía autoinmune". En el primer caso, Lindgren et al realizaron un estudio de 45 sujetos con SS de los que $12(27 \%)$ tenían lesión hepática, en concreto una colestasis bioquímica. En 4 de éstos últimos se llegó al diagnóstico de CBP mediante biopsia y en dos, de hepatitis crónica autoinmune ${ }^{7}$. Los autores concluyeron diciendo que la función hepática anormal en pacientes con SS es frecuente y puede ser indicador de enfermedad hepática autoinmune. Manthorpe et al encontró anticuerpos antimembrana hepática (LMA) en el $13 \%$ de pacientes con SS primarios, anticuerpos antimitocondriales (AMA) en el 5\% y anticuerpos antimúsculo liso en el 30\%. Estas cifras respecto al SS secundario resultaron ser mayores $(30,23$ y $37 \%$ respectivamente). Así pues, la conclusión de los autores señala que la presencia de dichos anticuerpos apoya la existencia de enfermedad inflamatoria hepática ${ }^{8}$. Con respecto a la CBP se debe aclarar que es otro ejemplo de desorden autoinmune que se ha asociado a SS y ya se conoce desde los trabajos de Goldin et al y Alarcón-Segovia et al publicados hace casi 20 años ${ }^{9,10}$. Sobre la búsqueda referida a la prevalencia de SS en los pacientes afectos de hepatopatía autoinmune, hay que destacar el estudio de Tsianos et al en el que revisaron a 38 pacientes con CBP en los cuales buscaban síntomas o signos objetivos de $\mathrm{SS}^{11}$. Los resultados fueron la existencia de síntomas de SS en 18 pacientes $(47,4 \%)$ pero sólo lo bastante intensos como para ser tratados en 4 sujetos $(10,5 \%)$. Los cambios histológicos diagnósticos de SS aparecieron en 5 individuos $(26,3 \%)$ todos ellos con síntomas compatibles con SS pero sólo tres con test de Schrimer anormal. Otro estudio similar al anterior fue el llevado a cabo por Udenfeldt et al en el que se apreció la presencia de queratoconjuntivitis seca y/o xerostomía en el $27 \%$ pacientes con CBP (12). Bodenheinmer et al se atreve a señalar que el desorden autoinmune más frecuente asociado a CBP es el SS, con una prevalencia entre un $69-81 \%{ }^{13}$.

Como conclusión diremos que la asociación entre el SS y la afectación del hígado (en nuestro caso alteración de bioquímica hepática con colestasis) ha sido suficientemente estudiada y confirmada. En 
los dos casos que presentamos, la alteración de la bioquímica hepática con colestasis nos ayudó a llegar a su diagnóstico. Por tanto desde el punto de vista de AP, los pacientes que de forma casual en una analítica presenten afectación hepática, sobre todo con alteración de las enzimas colestásicas, no debemos quedarnos únicamente en el despistaje de hepatitis vírica sino ir más allá y preguntarnos por una posible etiología auoinmune sin olvidar el SS con sus marcadores más específicos, anti-Ro y anti-La, además de realizar una entrevista dirigida a sus síntomas clave como son la sequedad de mucosas ocular o bucal.

Si la sospecha existe, basta con llevar a cabo una prueba sencilla, barata y de fácil disponibilidad en AP como es el test de Schrimer. Sin embargo, debemos aclarar que para la correcta clasificación de la afectación hepática, ya sea hepatitis autoinmune, CBP o colestasis sin lesión hepática, debemos re- currir a una atención especializada para la realización de la biopsia hepática.

Una vez más queda demostrado que la consulta de AP es un lugar estratégico en la detección de patologías que afectan a múltiples órganos y/o sistemas ya que en nuestro caso la visión de conjunto del paciente, así como el seguimiento en el tiempo, es más habitual que en las diferentes especialidades a las que los sujetos o nosotros mismos consultamos por problemas que, en principio, parecen puntuales.

\section{CORRESPONDENCIA:}

J.A. Mengual Pavía

Passeig del Saladar, 75-3-9

03700 Denia (Alicante)

\section{Bibliografía}

1. Gabriel Botella F, Monteagudo Castro C, Labios Gómez M, Balaguer Martínez JV, Sempere Montes J, Guiral Oliva M V. Síndrome de Sjögren: Una nueva aproximación diagnóstica. An Med Interna 1998; 15 (2): 287-90.

2. Díaz López C. El síndrome de Sjögren. Manual S.E.R. de las enfermedades reumáticas. $3^{\mathrm{a}}$ ed. Madrid: Editorial Panamericana, 2000. p. 335-43.

3. Bosch Gil JA. Síndrome Sjögren. An Med Interna 1999; 16 Supl. 1: 10-9.

4. Vitali C, Bombardineri S, Mouspoulos HM, Balestrieri G, Bencivelli W, Bernstein RD, et al. Preliminary criteria for clasification of Sjögren syndrome. Arthritis and Rheum 1993; 36: 340-7.

5. Coll J. Diagnóstico Síndrome de Sjögren. Med Clin 1995; 105: 778-9.

6. Furuya T, Tateishi M, Nishinorita M. Primary biliary cirrhosis in patients with Sjögren syndrome. Nippon Rinsho 1995; 53 (10): 2536-9.
7. Lindgren S, Manthorpe R, Eriksson S. Autoinmune liver disease in patients with primary Sjögren syndrome. Hepatol 1994 (3): 354-8.

8. Manthorpe R, Permin H, Tage-Jensen U. Antibodys in Sjögren syndrome with special refrence to liver-cell membrane antibody (LMA). Scand J Rheumatology 1979; 8: 168-72.

9. Goldin PL, Smith M, Williams R. Multisystem involment in chronic liver disease. Am J Med 1973; 55: 772-822.

10. Alarcón-Segovia D, Díaz E, Fishbern E. Features of Sjögren syndrome in primary biliary cirrhosis. Ann Intern Med 1973; 79: 31-6.

11. Tsianos EV, Hoofnagle J, Fox P, Alspaugh M, Jones EA, Schafer DF, et al. Sjögren syndrome in patients with primary biliary cirrhosis. Hepatology 1990; 11: 730-4.

12. Uddenfeldt P, Danielsson A, Forssell A. Features of Sjögren syndrome in patients with primary biliary cirrhosis. 1991; 230: 443-8.

13. Bodenheimer H, Schafner F. Primary biliary cirrhosis and the inmune system. Am J Gastroenterol 1979; 72: 285-96. 